\title{
A SIGNIFICAÇÃO DO GROTESCO NA NARRATIVA DE TESTEMUNHO DE PRIMO LEVI.
}

\author{
Viviane Dantas Moraes ${ }^{1}$
}

Resumo: O grotesco, para Wolfgang Kayser, é um conceito que possui como essência estética a deformidade. Esta deformidade, normalmente, se revela por meio da escritura do corpo e imagens que causam abjeção. Primo Levi, ao relatar sua experiência enquanto prisioneiro nos campos de concentração rememora em sua narrativa algumas cenas que se aproximam fortemente do grotesco enquanto imagem e significação. Na sua maioria, se tratam de cenas fortes que, normalmente, se referem às pestes que assolavam o lugar, como os piolhos, assim como as doenças que debilitavam o corpo e as feridas crônicas nos pés. Em uma situação como esta, em que relembrar é doloroso, pois envolve a questão traumática, a tentativa de avaliar a própria dor muitas vezes se torna insuportável, por isso, é possível observar nestas descrições grotescas, aliás, algo frequente no campo de concentração, uma tentativa de externar e revelar um estado de alma em agonia.

Palavras-chave: Grotesco, testemunho, Primo Levi.

\begin{abstract}
The grotesque one, for Wolfgang Kayser, is a concept that it possesses as esthetic essence the deformity. This deformity, normaly, shows by means of the writing of the body and images that cause abjection. Primo Levi, when telling its experience while prisioner in the concentration camps recollects in its narrative some scenes that come close strongly to the grotesque one while image and signification. In its majority, if they deal strong scenes that, normally, if they refer to the plagues that devastated the place, as the lices, as well, as the deseases that debilitated the body and the chrounic wounds in the feet. In a situation as this, where to recall is painful, because it involves the traumatic question, the attempt to evaluate proper pain mainy times becomes unbearable, therefore, is possible to observe in these grotesque descriptions, by the way, something frequent in the concentration camp, an attempt to externarand to disclose a state of soul in agony.
\end{abstract}

Palavras-chave: Grotesque, certification, Primo Levi.

\footnotetext{
${ }^{1}$ Mestre em Estudos Literários pela UFPA. Professora de Língua e Cultura francesa na Universidade da Amazônia (UNAMA).E-mail: viviane.danttas@gmail.com
} 


\section{INTRODUÇÃO: UMA CONCEPÇÃO DO GROTESCO}

Ao condensarmos a ideia de Realismo grotesco, de Mikhail Bakhtin, em que o grotesco representa o rebaixamento corporal e espiritual de tudo que é considerado elevado à concepção de Wolfgang Kayser sobre o conceito, no qual o teórico considera que o estranhamento presente nas formas grotescas está ligado à relação aparência e essência, percebemos que os pontos de vista traduzem o pensamento de Victor Hugo ao atribuir ao grotesco sua essência estética: a deformidade. Segundo Victor Hugo (apud Bakhtin, 2008, p.38), “o aspecto essencial do grotesco é a deformidade e a estética do grotesco é em grande parte a estética do disforme". Esta deformidade pode se demonstrar de diversas maneiras a partir da escritura do corpo, visto que esse elemento é a ponte necessária para revelar conflitos ocultos.

A partir dessa premissa, considera-se possível observar na narrativa de testemunho de Primo Levi, no que diz respeito às suas obras É isto um homem? (1958) e em A trégua (1958), um significação do grotesco que se configura nos seus relatos de experiência enquanto prisioneiro no campo de concentração nazista. A possibilidade dessa relação surge a partir do momento em que se observa na escritura do testemunho do autor uma linguagem que se utiliza de expressões e descrições que remetem à deformidade aparente e essencial do campo que, na verdade, são vistas como uma tentativa de descrever um estado emocional. No entanto, sabe-se que relembrar uma vivência traumática é doloroso e admitir claramente que as atrocidades, sujidades, pestilências e tudo o mais que atuava no lugar como meio de opressão fossem revelações de um sentimento intrínseco. Ou seja, o campo não é de fato o campo, mas a representação de uma subjetividade.

Para que essa análise fique mais clara, torna-se necessário anteriormente ao perscrutar os motivos que tornam a narrativa de testemunho de Primo Levi como representação do Grotesco, elucidar algumas informações sobre o conceito enquanto categoria estética.

O vocábulo "grotesco" surgiu no final do século XV, em Roma, na Itália, após escavações feitas em uma caverna, na então chamada Domus Aurea ou Palácio Dourado Neto, localizada em frente ao Coliseu. Durante os trabalhos de escavação, alguns desenhos foram encontrados nas paredes dessas grutas. Eram pinturas ornamentais antigas e desconhecidas que misturavam formas humanas com animais e plantas, daí destaca-se o aspecto animalesco do conceito enquanto imagem e significação. A partir das formas italianas grottesca e grottesco como derivações de grotta (gruta), local onde esses elementos foram encontrados, essa arte foi denominada de "grotesca".

Segundo Bakhtin (2008, p. 28), autor da denominação Realismo grotesco, essa descoberta surpreendeu os contemporâneos pelo jogo insólito, fantástico e livre das formas vegetais, animais e humanas que se confundiam e se transformavam entre si. O traço marcante do realismo grotesco é o "rebaixamento" do indivíduo que está em um plano elevado espiritual e ideal - e que passa a ser visto enquanto matéria orgânica em seu aspecto mais animalesco. O Realismo grotesco está intimamente ligado ao princípio da vida corporal e material, ou seja, a imagens do corpo, da bebida, da comida, da satisfação das necessidades naturais e da vida sexual. Segundo Victor Hugo (apud Bakhtin, 2008, p.38), "o aspecto essencial do grotesco é a deformidade e a estética do grotesco é em grande parte a estética do disforme". 
É evidente o destaque que a denominação Realismo grotesco dá ao aspecto corporal para expressar a deformidade. Nesse sentido, para Wolfgang Kayser, a expressão disforme que se compõe na escritura do corpo representa uma significação do grotesco que é mais essencial, e consequentemente mais existencial, ou seja, os conflitos interiores, a dor e o sofrimento anímico - ligado ao psiquismo - são, segundo Kayser, os fatores determinantes para a expressão corporal disforme. Portanto, para o teórico alemão é preciso observar que o que se encontra por detrás das expressões grotescas é a revelação de uma inquietação interior.

A partir do século XVI o vocábulo grotesco adquiriu outros significados além de um simples substantivo. Isso aconteceu, em princípio, nas artes plásticas, quando o termo passou a ser a denominação do estilo de pintura e arquitetura da época, sendo adotado pelos pintores italianos da Renascença, por exemplo, Rafael Sanzio (1483-1520) e seus discípulos. O grotesco começou a ganhar uma compreensão mais ampla enquanto categoria estética em meados do século XVIII. Nos dois séculos anteriores, o grotesco era rejeitado pela estética clássica, que primava pela harmonia, pois não era possível admitir algo que estivesse fora dos padrões de beleza.

No início do século XX o crítico literário alemão Wolfgang Kayser (2003) traz à tona um estudo apurado sobre a presença da estética do grotesco nas artes plásticas e na literatura no contexto da Modernidade. Conforme pensamos anteriormente na relação entre Realismo e grotesco, é coerente também esclarecermos a relação do grotesco com o Modernismo. O grotesco se revela uma das manifestações estéticas da Modernidade que exaltam, por meio da forma artística, as crises da existência humana. Em outras palavras, o absurdo do próprio existir é tão patente que se transporta e personifica o horror que está escondido na alma.

Segundo Kayser (2003, p. 30), na tentativa de se definir o conceito de grotesco enquanto categoria estética, a reflexão artística do século XVIII, sobretudo nas artes plásticas, foi feita primeiramente em torno do conceito de caricatura, objetivando julgar seu valor enquanto arte. Considerando que a caricatura é uma leitura disforme da realidade, constatou-se que essa característica se aproxima, em princípio, da estética do grotesco, ou seja, da deformidade. Desta maneira, por que não considerar o grotesco como arte? Nesse sentido, Kayser afirma que a obra de Pieter Brueghel, o Jovem (1564-1638)², pintor do século XVI, conhecido como "Brueghel dos Infernos", ajudou, de alguma forma, na consolidação do grotesco enquanto categoria artística, pois, suas pinturas foram consideradas:

as inteiramente fantásticas, ou, a bem dizer, as assim chamadas grotescas, onde $\mathrm{o}$ pintor, despreocupado com a verdade e a semelhança, se entrega a uma imaginação selvagem, e através do sobrenatural e do contra-senso dos seus produtos cerebrais, quer despertar com eles apenas gargalhadas, nojo, surpresa pela audácia de suas criações monstruosas. (Kayser, 2003, p. 31)

A passagem da Idade Média para a Idade Moderna significou o rompimento com as tradições morais e teológicas anunciando o triunfo da Razão, que se baseou na substituição de Deus pelas explicações da Ciência. A Modernidade, nesse sentido, representou a possibilidade de um mundo próspero, livre das amarras do passado tradicionalista, mas por outro

${ }^{2}$ Assim chamado para ser diferenciado do seu pai Pieter Brueghel, o Velho (1525-1569) que também foi pintor. 
lado, o homem se viu diante da instabilidade do novo e da segurança do antigo, tornando-se contraditório nos seus objetivos e nas suas certezas sobre a vida e sobre o mundo. A crise da existência — intensificada no século XX após a primeira guerra mundial (1914-1918) — em um mundo em constante transformação social, material e física, tem se tornado muito frequente no homem moderno que, ao se deparar com as modificações avassaladoras da modernidade, se sente perdido, sem saber o que fazer e frustrado, ao perceber a impossibilidade de acompanhar os passos rápidos das mudanças.

A Modernidade impulsiona o homem a mergulhar em um turbilhão de informação e de consumo que se renova a todo instante, inclinando-o a uma vida materialista. Ao se dar conta da efemeridade dos deleites que a modernidade proporciona sem poder acompanhar seu ritmo frenético, o homem começa a se entregar aos poucos a certa anomia ${ }^{3}$. Desta maneira, as consequências da modernidade vêm à tona: o isolamento social do indivíduo e o enfraquecimento de laços afetivos com o próximo e com o mundo. Não sabendo lidar com esses acontecimentos, o homem começa a indagar o valor de sua própria existência e, muitas vezes, chega ao desespero que se torna explícito, sendo o grotesco, portanto, o conceito mais adequado para evidenciar artisticamente esse sentimento hostil que assola o homem moderno. Nas artes plásticas, destacamos um bom exemplo que configura esse drama humano: a obra O grito (1893), do pintor norueguês Edvard Munch.

O filósofo Marshall Berman (1982) discute a questão da Modernidade e sua ligação com o espírito da sociedade dos séculos XIX e XX, ajudando-nos a compreender melhor a sua atmosfera. O autor elucida bem a relação entre "ser moderno" e ser contraditório, um dos traços da essência do grotesco modernista. Quanto ao caráter do "homem da modernidade", Berman afirma que "são todos movidos, ao mesmo tempo, pelo desejo de mudança - de autotransformação e de transformação do mundo em redor - e pelo terror da desorientação e da desintegração, o terror da vida se desfaz em pedaços" (Berman, 2007, p.21). A Modernidade rompeu, sobretudo, com os valores morais e teológicos cultivados na Idade Média.

Nesse contexto do que se denominou Modernidade e considerando suas modificações no espírito da sociedade destaca-se nesta discussão o cenário do campo de concentração nazista e as memórias pós-guerra dos prisioneiros. A atmosfera de desorientação e descrença se acentuou após a Segunda Guerra Mundial. Os milhares de judeus perseguidos, presos e mortos pelo regime nazista foram um marco de desumanidade. Os que conseguiram sobreviver, como o caso de Primo Levi que, impulsionado pela necessidade em contar sua experiência, em se fazer ouvir, publicou alguns livros de memorialísticos que, ao mesmo tempo, marcaram o surgimento de um gênero literário que a narrativa de testemunho. Entre essas obras estão É isto um homem? (1947), A trégua (1963) e o seu último e considerado o mais importante nessa linha Os afogados e os sobreviventes (1977). A voz de quem vivenciou uma catástrofe não é um elemento irrelevante. Segundo Seligmann-Silva (2005, p. 79):

O testemunho não deve ser confundido nem com o gênero autobiográfico nem com a historiografia - ele apresenta uma outra voz, um 'canto (lamento) paralelo', que se junta à disciplina histórica para colher traços do passado. [...] Ao invés de

\footnotetext{
${ }^{3}$ O termo anomia foi designado pelo sociólogo francês Emilie Durkheim (1858-1917). Refere-se ao estado de impotência, crises de identidade, e falta de objetivo de vida, sentimentos oriundos de mudanças aceleradas no mundo moderno.
} 
visar uma representação [pura] do passado, a literatura de testemunho tem em mira a sua construção a partir de um presente.

A palavra testemunho nesse sentido possui uma conotação forte pelo fato de que a memória vivida e sofrida por quem conta permanece "assombrada" pelo evento traumático o que muitas vezes pode interferir na fidelidade dos fatos acontecidos. É esse mesmo elemento que faz com que as descrições atrozes do campo sejam de maneira inconsciente uma revelação de um estado corporal e espiritual do narrador que se sente oprimido diante o poder e da impotência pela liberdade perdida.

\section{O TESTEMUNHO EXPRESSO NA ESCRITURA DO CORPO GROTESCO.}

Após o esclarecimento dos significados que o grotesco pode suscitar partimos para a análise proposta. Primo Levi, ao relatar sua experiência enquanto prisioneiro nos campos de concentração rememora em sua narrativa testemunhal algumas cenas que se aproximam fortemente do grotesco enquanto imagem e significação. Na sua maioria, tratam-se de cenas fortes que, normalmente, se referem às pestes que assolavam o lugar, como os piolhos, assim como as doenças que debilitavam o corpo, como a disenteria crônica e as feridas persistentes nos pés. Em uma situação como esta, em que relembrar é doloroso, pois envolve a questão traumática, a tentativa de avaliar a própria dor muitas vezes se torna insuportável, por isso, é possível observar nestas descrições grotescas, aliás, algo frequente no campo de concentração, uma tentativa de externar e revelar um estado de alma em agonia dentro de um conflito que se estabelece entre o lembrar, o relembrar e refletir sobre a própria condição.

É interessante observar que é justamente o refletir sobre a própria condição existencial o componente necessário para a composição do grotesco na narrativa, posto que fosse muito menos doloroso admitir um grotesco que se configura externamente para camuflar uma deformidade que está na dor de lembrar o sofrido. Nesse sentido, é notório que o primeiro livro de memórias do autor É isto um homem?, a partir do título, já nos revela um questionamento sobre a condição humana subjugada à condição animalesca, característica forte na caracterização do grotesco. Nos primeiros capítulos dos relatos, em que Primo Levi conta a sua ida e a sua chegada ao campo, é possível perceber uma alusão frequente à aparência do lugar. Em um dos momentos, o autor descreve o momento do banho matinal, em que os vários prisioneiros se encontram em um barracão:

Ao terminar [o banho], cada qual fica em seu canto, sem ousar levantar o olhar para os demais. Não há espelhos, mas a nossa imagem está aí na nossa frente, refletida em cem rostos pálidos, em cem bonecos sórdidos e miseráveis. Estamos transformados em fantasmas como os que vimos ontem à noite. (Levi, 1988, p.24)

O vocábulo "grotesco" aparece na narrativa algumas vezes, por exemplo, na tentativa de descrever a aura que acompanha a adaptação ao campo: "Por outra parte, o processo todo de inserir-se nesta ordem nova para nós, acontece de forma grotesca e fantástica" (Levi, 
1988, p.26). Esta citação, embora o autor não explique a intenção ao empregar a palavra, prenuncia o caráter interior do grotesco por meio de uma expressão disforme, como podemos observar no trecho a seguir, em que o autor relembra o sentimento coletivo após os primeiros dias da chegada e a conscientização da sua condição humana:

Aqui estou, então: no fundo do poço. Quando a necessidade aperta, aprende-se em breve a apagar da nossa mente o passado e o futuro. Quinze dias depois da chegada, já tenho fome regulamentar, essa fome crônica que os homens livres desconhecem; que faz sonhar, à noite; que fica dentro de cada fragmento de nossos corpos. [...] Já apareceram, no peito de meus pés, as torpes chagas que nunca irão sarar. Empurro vagões, trabalho com a pá, desfaleço na chuva, tremo no vento; mesmo meu corpo já não é meu; meu ventre está inchado, meus membros ressequidos, meu rosto túmido de manhã e chupado à noite; alguns de nós têm a pele amarelada, outros cinzenta; quando não nos vemos durante três ou quatro dias, custamos a reconhecer-nos. Era triste demais contar-nos, encontrar-nos cada vez em menor número, cada vez mais disformes, esquálidos. (Levi, 1988, p. 35)

O trecho acima demonstra a tomada de consciência do aprisionamento e da perda da liberdade. Acostuma-se, a partir de então, a viver ou a sobreviver no campo. É interessante notar que a dificuldade em relembrar a dor do sofrimento psíquico, a humilhação, a liberdade tolhida etc. é tão grande, a ponto de o testemunho muitas vezes ser mais descritivo, ou seja, o narrador opta por uma linguagem mais escancarada, mais literal. Esse fato não subjuga a semântica do texto, pois se relacionarmos esse aspecto à premissa do grotesco pode-se observar que, quando o escritor se refere à fome, aos membros ressequidos, à pele amarelada, ao ventre inchado e, sobretudo, às torpes chagas que nunca irão sarar, nos oferece por meio da linguagem, a escritura de um corpo grotesco que nos revela, na verdade, não apenas uma mera informação, mas nos quer demonstrar como ele se sente no mundo, diante dos outros e perante à opressão do poder do qual é obrigado a se submeter. Quanto a esse aspecto relacionado à linguagem na narrativa de testemunho, Reis (2007) reflete:

Na Europa, a literatura testemunho ganha impulso a partir dos relatos de sobreviventes do holocausto e se articula sobre a linha tênue da necessidade de narrar a barbárie e a insuficiência de linguagem diante do horror e do trauma, paradoxo que põe em cheque a relação entre o real e o ficcional, entre história e ficção. É possível a realidade verbal, de linguagem, traduzir um excesso de realidade "vivida"? No pós-guerra, Adorno questionava, no paradigmático ensaio Engagement, se "há sentido em viver quando existem homens que batem até que os ossos se quebrem no corpo", ao mesmo tempo em que se perguntava "se a arte ainda pode existir, se uma regressão do intelecto no conceito de literatura engajada não é sujeitada pela regressão da sociedade mesma"; e contesta sua pergunta afirmando que "a poesia precisa resistir a este veredicto; ser portanto de tal modo que não tome a si pela sua simples existência depois de Auschwitz, o cinismo o excesso de sofrimento real não permite o esquecimento. (Reis, 2007, p.78) 
$\mathrm{Na}$ citação acima, a autora em seu questionamento 'É possível a realidade verbal, de linguagem, traduzir um excesso de realidade vivida?' nos dá margem para uma resposta contundente, pois podemos respondê-la em afirmativa se a olharmos pelo prisma do grotesco, ou seja, a estética do grotesco se configura na linguagem descritiva que em alguns momentos se mostra aparentemente literal na narrativa memorialística de Primo Levi. Nesse sentido, complementa-se esse pensamento com a seguinte citação "Mas o próprio Levi é o primeiro a constatar a impotência das palavras diante da tarefa do testemunho: 'a nossa língua não tem palavras para expressar essa ofensa, a aniquilação de um homem"” (Seligmann-Silva, 2005, p.68). A linguagem descritiva de Primo Levi, que faz questão de apontar os, digamos, motivos de sofrimento humano no campo, possibilita ultrapassar os limites desse próprio corpo nos revelando uma tentativa de explicar, na verdade, um sentimento coletivo a partir de uma visão e sentimentos individuais.

É importante ressaltar que as palavras de Primo Levi - neste momento faz-se referência à citação de Seligmann-Silva no parágrafo anterior - revelam que a ofensa e a aniquilação do homem não conseguem ser plenamente expressas por meio da linguagem. No entanto, a identificação do grotesco na sua narrativa consegue vislumbrar que por meio das descrições utilizadas pelo narrador consegue-se perceber, sim, essa aniquilação humana refletida na escritura do corpo em decadência e sofrimento. Ao declarar isso, é possível que o próprio Primo Levi não tivesse consciência de que, ao mesmo tempo em que descobria e analisava o campo, desnudava a si mesmo.

É expressamente notório nos dois primeiros livros memorialísticos de Primo Levi, $E$ isto um homem? e A trégua o caráter bastante descritivo que o autor dá à narrativa, seja do campo, seja dos outros colegas prisioneiros. No entanto, o olhar do autor, apesar das descrições recorrentes, vai além do ôntico, por isso é viável perceber nessa aparência uma forte essência. No início de A trégua (1963) em que ele relata o fim da guerra e o início da tentativa de volta para casa, o cenário que ele nos oferece do campo se aproxima de uma visão quase apocalíptica. Os banhos, segundo ele, eram 'banhos de humilhação, banhos grotesco-demoníacos'. Nesta mesma obra há uma revelação do narrador em que se pode refletir sobre a natureza do grotesco:

[...] ninguém pôde mais do que nós [referência aos prisioneiros do campo] acolher a insanável natureza da ofensa, que se espalha como um contágio. É absurdo pensar que a justiça humana possa extingui-la. Ela é uma inexaurível fonte do mal: quebra o corpo e a alma dos esmagados, os destrói e os torna abjetos; recai como infâmia sobre os opressores, perpetua-se como ódio nos sobreviventes, e pulula de mil maneiras, contra a própria vontade de todos, como sede de vingança, como desmoronamento moral, como negação, como fadiga, como renúncia. (Levi, 2010, p. 11)

A escritura do corpo - e a citação acima reforça esse aspecto - nos apresenta um corpo como símbolo da decadência e até mesmo enquanto um meio de denúncia, ou seja, é necessário falar como se sente e quem provoca esse sentimento. Toda essa atmosfera traz à tona a deformidade, o rebaixamento corporal e espiritual, características que configuram a 
estética do grotesco que permeia e se entremeia na narrativa de testemunho de Primo Levi, em aparência e em essência.

\section{REFERÊNCIAS}

BAKHTIN, Mikhail. A cultura popular na Idade Média: o contexto de François Rabelais. Tradução Yara Frateschi Vieira. 6. ed. São Paulo: Hucitec, 2008.

KAYSER, Wolfgang. O grotesco. Tradução J. Guinsburg. São Paulo: Perspectiva, 2003.

LEVI, Primo. É isto um homem? Tradução de Luigi del Re. Rio de Janeiro: Rocco, 1988.

LEVI, Primo. A trégua. São Paulo: Companhia das Letras, 2010.

SELIGMANN-SILVA, Márcio. O local da diferença: ensaios sobre memória, arte, literatura e tradução. São Paulo: Editora 34, 2005.

REIS, Lívia. Testemunho como construção da memória. In: Cadernos de Letras da UFF. Dossiê: Letras e Direitos Humanos, n. 33, p. 77-86, 2007. 